

\title{
OS MODELOS CRÍTICOS DE MAX HORKHEIMER
}

\author{
MAX HORKHEIMER AND THE FOUNDATIONS OF THE FRANKFURT SCHOOL.
}

de Abromeit, John. Cambridge: Cambridge University Press, 2011.

\author{
MARCOS NOBRE \\ ADRIANO JANUÁRIO \\ RAPHAEL CONCLI \\ PAULO YAMAWAKE
}

[1] The dialectical imagination: a history of the Frankfurt School and the Institute of Social Research 1923-50. Boston: Little, Brown and Co., 1973. [Ed.bras.: A imaginação dialética: história da Escola de Frankfurt e do Instituto de Pesquisas Sociais 1923-1950. Trad. Vera Ribeiro. Rio de Janeiro: Contraponto, 2008].

[2] Die Frankfurt Schule. Geschichte, Theoretische Entwicklung, Politische Bedeutung. Munique:Hanser, 1986. [Ed. bras.: A Escola de Frankfurt: história, desenvolvimento teórico, significaçãopolitica. Trad. Vera de Azambuja Harvey. São Paulo: Difel, 2002].
Max Horkheimer and the foundations of the Frankfurt School, de John Abromeit, vem somar-se a uma dupla já estabelecida de estudos de referência sobre o nascimento e o desenvolvimento da Teoria Crítica (que, em alguns lugares, como nos Estados Unidos e na França, ainda é conhecida pelo equívoco rótulo "Escola de Frankfurt"): A imaginação dialética, de Martin Jay ${ }^{1}$, e A Escola de Frankfurt, de Rolf Wiggershaus ${ }^{2}$. O livro de Abromeit não tem a abrangência desses dois. Dedica-se apenas ao exame aprofundado de parte da trajetória intelectual de Horkheimer, de seu nascimento, em 1895, até o ano de 1941, que marca uma redução ao mínimo das atividades do Instituto de Pesquisa Social em Nova York e uma virada no pensamento do teórico social. Mas é de Horkheimer que se trata: as fases de sua produção examinadas no livro são não apenas altamente profícuas como também inaugurais, o queé sugerido pela ambição teórica bem mais ampla estampada no subtítulo: apresentar nada menos do que "as fundações da Escola de Frankfurt".

Nessa comparação com os dois outros estudos de referência sobre a Teoria Crítica, importa também não apenas a distância temporal que os separa, mas a diferença de fontes. John Abromeit pesquisou em um momento em que já se encontrava em pleno funcionamento o Arquivo Max Horkheimer e em que já tinha sido completada a publicação dos Escritos reunidos pela editora Fischer. Além disso, o livro pretende não apenas reconsiderar as "fundações" da Teoria Crítica, mas recuperar o modelo crítico formulado por Horkheimer para levar adiante essa tradição intelectual. Para isso, parte de um diagnóstico do campo crítico marcado por duas balizas fundamentais. De um lado, quer abrir caminhos que não se fechem na conhecida "aporia" da Dialética do Esclare- 
cimento $^{3}$. De outro lado, aceita implicitamente o desafio colocado pela teoria crítica de Habermas, ao indicar que é possível construir uma alternativa a essa aporia a partir do movimento teórico fundamental realizado por Horkheimer nos anos 1925-1931, que teria significado nada menos do que uma "ruptura com a filosofia da consciência". Com isso, torna-se possível reconstruir de outro modo o próprio desenvolvimento da Teoria Crítica, de maneira a fugir à interpretação de conjunto consolidada por Habermas ${ }^{4}$ :

Uma biografia intelectual que aspire a se manter fiel ao espírito crítico de Horkheimer - como esta pretende - deve não apenas tentarapresentar suas ideias em toda sua complexidade e radicalidade para assim salvá-las da onda de amnésia e conformismo que ameaçam devastar o presente. Tal obra deve também procurar identificaros fatores sociais e históricos que condicionaram sua teoria crítica nos vários estágios de seu desenvolvimento. Só assim será possível o direcionamento para a importante tarefa final de determinar quais aspectos da teoria crítica de Horkheimer ainda são relevantes no presente e quais devem ser revisados ou abandonados 5 .

Se a explicitação desse engajamento e dessa tomada de posição já distingue de saída o livro de John Abromeit dos livros de referência de Martin Jaye de RolfWiggershaus, a sua escolha de objeto aprofunda as diferenças. A grande sacada do livro pioneiro de Martin Jay - orientador de John Abromeit, cuja tese de doutorado foi a base para a redação do livro - esteve em realizar a "biografia" intelectual de uma instituição (o Instituto de Pesquisa Social) entre as décadas de 1920 e 1940, o que lhe permitiu escapar à ideia confusa (e redutora, como mostrou o próprio Jay em seu livro) de uma "Escola". Essa abordagem lhe permitiu ainda mostrar em ato a ideia-força do "materialismo interdisciplinar", que guiou o trabalho coletivo a partir dos anos 1930.

A escolha de Abromeit não é menos engenhosa: reconstruir o momento inaugural dessa vertente intelectual permite abrir o campo das possibilidades de desenvolvimento teórico, trilhadas ou não, tanto em relação ao passado como em relação ao presente, concretizadas em uma direção determinada, abandonadas ou retomadas. Não é outra a razão pela qual o livro se encerra em 1941, com a Dialética do Esclarecimento já a caminho, momento em que Horkheimer decide por tomar um dos muitos possíveis caminhos que ele mesmo havia aberto. A consolidação dessa virada está no artigo “The end of reason”, de $1942^{6}$, cuja versão em alemão tem por título "Razão e autopreservação". A partir daí, segundo John Abromeit, o "abandono por Horkheimer do modelo de uma dialética da sociedade burguesa levou ao desaparecimento de distinções-chave que tinham estruturado seu trabalho anterior tanto em nível sincrônico como diacrônico"7.
[3] Adorno, T. e Horkheimer, M. Dialética do Esclarecimento:fragmentos filosóficos. Trad. Guido de Almeida. Rio de Janeiro: Zahar, 1985.

[4] Habermas, J. Theorie des kommunikativen Handelns, Band 1. Handlungsrationalität und gesellschaftliche Rationalisierung. Frankfurt am Main: Suhrkamp, 1995.

[5] Abromeit, J. Max Horkheimer and the foundations of the Frankfurt School. Cambridge: Cambridge University Press, 2011, p. 170.

[6] Horkheimer, M. "The end of reason". Studies in Philosophy and Social Sciences, vol. IX, Nova York, 1942.

[7] Abromeit, op.cit., p.395. 
[8] Abromeit,op.cit., p.392.

[9] Lukács, G. História e consciência de classe. Estudos sobre a dialética marxista. Trad. de Rodnei Nascimento. São Paulo: Martins Fontes, 2003.
A reconstrução do projeto de uma "antropologia da época burguesa", conjugado a uma determinada apropriação do "materialismo" e à ideia de um livro sobre "lógica dialética", surge como configuração por excelência do trabalho de Horkheimer nos anos 1930. O livro de John Abromeit está armado de maneira a mostrar como esse projeto tinha várias possibilidades de desenvolvimento, sendo o resultado dos anos 1940 (que gira em torno da Dialética do Esclarecimento) apenas uma das suas possíveis realizações. Com isso, Abromeit aponta também, implicitamente, que seria possível continuar esse projeto em sentido diverso da Dialética do Esclarecimento no momento presente.

Esse sentido diverso pode ser relacionado a uma tendência atual no campo crítico de tematizar o afastamento da Teoria Crítica de certa concepção de pesquisa empírica. Pois retomar e pôr em relevo os trabalhos de Horkheimer anteriores a 1941 possui também essa intenção, embora não explicitamente declarada, de mostrar os vínculos desse período de sua produção com um determinado modo de realizar pesquisa empírica desenvolvida então no Instituto de Pesquisa Social. O livro de Abromeit pode ser lido também como uma defesa de uma maneira possível de articular teoria social e pesquisa empírica, da qual os trabalhos de Horkheimer da década de 1930 seriam exemplares.

Se, após a leitura do livro, a estatura intelectual atribuída a Horkheimer parece mais do que justificada, por outro, a reconstrução do seu modelo crítico dos anos 1930 nesses termos é, por exigir ênfase na originalidade das formulações, pouco convincente. Pode ser que John Abromeit tenha razão em seu diagnóstico de que houve "uma forte tendência na literatura secundária a subsumir a obra de Horkheimere de Adorno a um conceito mais geral de 'marxismo ocidental', que tem como ponto de partida a ênfase metodológica de Lukács no conceito de totalidade, no de forma-mercadoria e no de reificação". Mas combater essa tendência — vale dizer, em boa medida, combater a versão de Habermas do desenvolvimento da Teoria Crítica - não exige necessariamente se colocar a tarefa nos termos em que pôs o livro: "Um dos principais objetivos deste estudo como um todo foi o de demonstrar que o caminho de Horkheimer para a Teoria Crítica foi independente daquele de Lukács e de Adorno"8.

Afirmar, por exemplo, que as formulações de Horkheimer dos anos 1930 têm por pano de fundo conceitual as formulações de História e consciência de classe ${ }^{9}$, de Lukács, em nada diminui a originalidade do então diretor do Instituto de Pesquisa Social. Pelo contrário, apenas torna mais precisa essa originalidade, dando-lhe maior substância. Isso se exprime até mesmo em oscilações argumentativas sintomáticas: "Como mostraram Michiel Korthals e Ferio Cerruti, Horkheimer não se apropriou do conceito de totalidade de Lukács seja nesse período, seja posteriormente", o que contrasta com uma afirmação poucas linhas 
adiante: "Depois de sua ruptura com Hans Cornelius, Horkheimer usaria o conceito de totalidade tanto em termos metodológicos como substantivos em sua teoria social, mas permaneceram importantes diferenças em relação a Lukács"ı.

De um lado, John Abromeit propõe uma mudança de foco extremamente fecunda: retirar os escritos de Horkheimer da rubrica abstrata da "metodologia" de maneira a mostraro vínculo indissolúvel, no campo da Teoria Crítica, entre a sistematização teórica e a investigação empírica. Com isso, consegue não apenas dar ao projeto de uma "Antropologia da época burguesa" (e, em especial, ao artigo "Egoísmo e movimento de libertação" ${ }^{11}$ o destaque e centralidade que merece, mas consegue despertar o interesse com respeito às possíveis linhas de continuidade desse projeto no momento atual. De outro lado, entretanto, esse movimento muitas vezes acaba por reduzir a importância de outros textos do período que merecem pelo menos igual destaque, como é o caso de "Teoria Tradicional e Teoria Críti$\mathrm{ca}^{\prime \prime 2}$. Assim como teria sido necessário atribuir pesos diferentes a diferentes influências teóricas, seria necessário também distinguir as diferentes estaturas de textos que possuem temas tão variados; uma análise mais de perto desses textos apontam que não são todos de mesma densidade e fecundidade.

Seja como for, é já muito impressionante a segurança e o interesse no manejo simultâneo de tantas fontes de alta densidade.A estratégia adotada por John Abromeit suplanta largamente essas possíveis objeções pelas possibilidades de leitura e de caminhos para a renovação da Teoria Crítica que seu livro oferece. Não por último porque o livro, no seu conjunto, é um plaidoyer pelo pluralismo e pelo diálogo no interior do campo crítico, sem em nenhum momento abdicar dos necessários embates teóricos que marcam a vitalidade dessa tradição.

De maneira consequente, o objetivo de abrir um leque muito mais amplo de possíveis caminhos para a Teoria Crítica determina também a estrutura do livro. Aênfase na fase decisiva de formação de Horkheimer (1925-1931) prepara a apresentação das muitas linhas de desenvolvimento que marcaram o período seguinte (1932-1941). E, no entanto, a periodização foi estabelecida a partir da articulação conceitual da trajetória de Horkheimer, e não a partir de eventos histórico-mundiais como a crise de 1929, a ascensão do nazismo ao poder, em 1933, ou a eclosão da Segunda Guerra Mundial, em 1939. A falta dessa referência a eventos histórico-mundiais é de grande importância, tanto pela centralidade da noção de "diagnóstico de tempo" no campo da Teoria Crítica quanto pelo próprio gênero do livro, uma "biografia intelectual": não são os sucessivos diagnósticos de tempo de Horkheimer nesse período especialmente conturbado que estruturam o livro.
[10] Abromeit, op. cit., p. 82.

\begin{abstract}
[11] Horkheimer, M. "Egoismus und Freiheitsbewegung". In: Gesammelte Schriften. Band 4: Schriften 1936-1941. Org. A. Schmidt. Frankfurt: Fischer, 1988, pp.9-88.
\end{abstract}

[12] Idem, "Traditionelle und kritische Theorie". In Gesammelte Schriften. Band 4: Schriften 1936-1941, op. cit., pp.162-216. 
[13] Horkheimer, M. "Zur Antinomie der teleologischen Urteilskraft". In: Gesammelte Schriften. Band 2: Schriften 1922-1932. Org. A. Schmidt. Frankfurt: Fischer, 19885 , pp. 15-72.
Desde a introdução, Abromeit levanta, mediante a leitura e a organização dos textos de Horkheimer do período, pelo menos cinco temas que contribuem para jogar uma nova luz na Teoria Crítica hoje: "história intelectual materialista", "história sociopsicológica", "antropologia da época burguesa”, uma "abordagem verdadeiramente interdisciplinar para a Teoria Crítica" e "pensamento pós-metafísico". Mais do que uma enumeração de temas, é uma tese de leitura que procura mostrar que a obra de Horkheimer extrapola os ensaios metodológicos - nos quais se concentram a maioria dos comentadores. Ao dar ênfase a esses novos temas, Abromeit introduz uma nova organização na obra de Horkheimer.

Max Horkheimerand the foundations of the Frankfurt School possui nove capítulos e dois excursos, além de uma introdução e um epílogo. A primeira seção (capítulos 1 e 2) pretende reconstruir o período que vai desde a infância de Horkheimer até 1925, ano em que escreve sua tese delivre-docência[Habilitationsschrift], intituladaZurAntinomie derteleologischen Urteilskraft [Sobre a antinomia do juízo teleológico]13, apresentada na Universidade de Frankfurt. O primeiro capítulo se concentra na infância e adolescência, destacando suas primeiras experiências emocionais, políticas e intelectuais, período em que Horkheimer escreve uma série de textos literários. Já o segundo capítulo - centro dessa primeira seção - trata dos anos como estudante em Frankfurt, nos quais Horkheimer entra em contato com as principais correntes teóricas que estavam em seu estágio "mais avançado", mais especificamente, com os avanços na filosofia, na psicologia e na sociologia. A exposição em maior detalhe desse período de estudos iniciais de Horkheimer tem, para Abromeit, o objetivo de primeiramente se contrapor aos comentadores que não atribuem qualquer importância teórica a essa fase. Embora Horkheimer não tenha produzido nesse período seu modelo crítico mais acabado, Abromeit sustenta que é nesse momento - entre 1920 e 1925 - que surgem alguns elementos importantes do modelo da década de 1930.

Segundo Abromeit, esse período da formação acadêmica fornece a Horkheimer três elementos centrais que acabaram por reverberar na fase madura do desenvolvimento de sua "Teoria Crítica primeira" (early Critical Theory) na década de 1930. O primeiro desses elementos é a aproximação e o interesse de Horkheimer pela pesquisa empírica, utilizando-se dessas últimas - desenvolvidas pela Gestalt - para se contrapor aos neokantianos do início do século. Essa contraposição crítica, segundo Abromeit, é justamente o escopo de sua tese de livre-docência. O segundo elemento que Horkheimer desenvolve é o conceito de "totalidade", esboçado a partir de seu contato mais direto com a psicologia de modo geral. O último elemento destacado nesse período é a ideia de unidade entre "razão prática e teórica", que será crucial 
para seu modelo crítico dos anos 1930. Nesse quadro geral surge pela primeira vez a ideia de "interdisciplinaridade", que será um dos elementos principais da Teoria Crítica de Horkheimer na década de 1930.

A segunda seção do livro (capítulos 3,4 e 5) cobre o período 1925 a 1931, culminando com o momento em que Horkheimer assume a direção do Instituto de Pesquisa Social de Frankfurt.A principal tese desse bloco de capítulos é a de que a Teoria Crítica primeira de Horkheimer teria se constituído, ainda que em linhas gerais, em meados dos anos 1920, e não apenas quando assume a direção do instituto, como defende a grande maioria dos comentadores.

No capítulo 3, Abromeit apresenta a intenção de Horkheimer de construir uma "interpretação materialista da filosofia moderna". O início desse projeto marca seu afastamento de Hans Cornelius e da "filosofia da consciência" no momento em que Horkheimer se torna Privatdozent em Frankfurt. Para Horkheimer, um dos principais problemas da "filosofia da consciência" é seu afastamento das condições históricas nas quais seus conceitos surgem. Com o intuito de evitar esse problema, ele desenvolve suas teses sobre a "interpretação materialista da história da filosofia moderna”, tomando o seu surgimento como vinculado ao surgimento da "época burguesa". Abromeit ressalta que Horkheimer tentava superar a "filosofia da consciência" através do "materialismo", isto é, vincular a "filosofia da consciência" ao surgimento da "época burguesa". Nesse momento, Horkheimer dá os primeiros passos para constituir uma teoria social própria, o que o faz iniciar seus estudos do pensamento de Marx com o objetivo de construir uma "teoria sociológica adequada" 14.

Nesse sentido, para Abromeit, a obra Dämmerung:Notizen in Deutschland [Crepúsculo: notas na Alemanha ${ }^{15}$ serve como importante fio condutor de seu argumento mais geral para essa fase da produção de Horkheimer. Publicada somente em 1934, mas cujos excertos são datados do período de 1926 a 1931, e sob o pseudônimo de Heinrich Regius, Dämmerung representaria uma tentativa de atualizar a teoria de Marx a partir da ideia de "subjetividade", sendo esta vinculada ao modo como a sociedade capitalista produz e reproduz seus próprios meios. Para Abromeit, Dämmerung se utiliza de aforismos, anedotas, metáforas e exemplos concretos para expressar as tendências sociais mais gerais da sociedade capitalista, assim como expressa também os mecanismos próprios desse modo de produção, os quais estão incrustados na sociedade. Em Dämmerung surge a ideia de que a "epistemologia" daquele momento não seria "consciente de suas determinações sociais" e, nesse sentido, ela acaba por reforçar e justificar as condições injustas da sociedade capitalista. Horkheimer pretende com esse escrito defender uma "individualidade concreta" contraposta ao "capitalismo monopolista". É nessa obra que ele teria
[14] Abromeit, op.cit., p.141.

[15] Horkheimer, M. "Dämmerung. Notizen in Deutschland". In: Gesammelte Schriften. Band 2: Schriften 1922-1932, op. cit., pp. 312-452. 
[16] Abromeit,op.cit.,p. 200.

[17] Ibidem, p. 207

[18] Ibidem, p. 227.

[19] Horkheimer, M. "Materialismus und Metaphysik". In: Gesammelte Schriften. Band 3: Schriften 19311936. Org. A. Schmidt. Frankfurt: Fischer, 1988, pp. 70-105. [Trad. bras. "Materialismo e metafísica". In: Horkheimer, M. Teoria critica I: uma documentação. Trad. de Hilde Cohn. São Paulo: Perspectiva/EDUSP, 1990.]

[20] Idem, "Materialismus und Moral". In: Gesammelte Schriften. Band 3: Schriften 1931-1936, op. cit., pp. 111-149. [Trad. bras. "Materialismo e moral". In: Horkheimer, Teoria critica I, op. cit.] começado a esboçar uma vinculação entre a pesquisa empírica e uma possível renovação do marxismo.

Essa necessidade de renovação do marxismo vinculado à pesquisa empírica fez com que Horkheimer levasse adiante a integração da psicanálise à teoria contemporânea da sociedade, objeto de discussão no capítulo 5.Para Abromeit, as investigações empíricas de Erich Fromm realizadas no final da década de 1920 foram cruciais para o desenvolvimento da Teoria Crítica. Após relatar como Horkheimer e Fromm se conheceram, assim como as aproximações teóricas de ambos, Abromeit passa a apresentar o "lugar teórico da psicanálise no pensamento de Horkheimer", "uma teoria materialista da subjetividade que pode ajudar a explicar melhor a consciência das ações individuais e dos grupos sob determinadas condições"16. Evitando a categoria de "inconsciente coletivo", Fromm direciona suas análises para as "experiências individuais" e de "grupos que sofrem a mesma pressão" ${ }^{17}$, isto é, seu intuito é observar o indivíduo concreto num contexto histórico determinado. Essa perspectiva foi incorporada pelo primeiro modelo crítico de Horkheimer. No contexto dessa colaboração surgiu o trabalho $A$ classe trabalhadora na Alemanha de Weimar. Abromeit considera esse o "primeiro trabalho da Teoria Crítica", tomando esse período como aquele em que Horkheimer começa a traçar as linhas de seu primeiro modelo crítico.

Não obstante, Abromeit registra uma mudança no pensamento de Horkheimer a partir do momento em que assume a direção do instituto. Essa mudança teria se dado justamente porque Horkheimer disporia então de um aparato institucional para implementar seu projeto de Teoria Crítica. Cada capítulo do "coração" do livro, a sua terceira seção (capítulos 6,7 e 8), pretende expor um dos três conceitos mais importantes para a Teoria Crítica "durante este momento particular"18, uma espécie de convergência e concentração de temáticas ainda mais amplas do período anterior: "materialismo" (cap. 6), "antropologia da época burguesa" (cap.7) e, por fim, "lógica dialética" (cap. 8).

No curto capítulo 6, Abromeit apresenta o conceito de materialismo em Horkheimer a partir de dois temas - que se referem a dois textos da primeira metade da década de 1930 - nos quais seus escritos incidem: "Materialismo e metafísica"19 e "Materialismo e moral"20. O materialismo, segundo Abromeit, surge primeiramente como uma espécie de "negação determinada" do "idealismo". Ele aponta que, para Horkheimer, os princípios universais de certas teorias expressam, na verdade, interesses particulares de "grupos" em momentos históricos determinados. Nessa expressão de interesses particulares em princípios universais, Horkheimer entende que "os conceitos", de modo geral, vinculam-se às classes sociais bem como à posição que estas ocupam na estrutura histórica e social. É nesse sentido que o 
"materialismo" surge nesse período também como tentativa de compreender a "moralidade", na medida em que tenta compreender como "a moralidade moderna se tornou a moralidade burguesa". Registre-se aqui, de passagem, uma dificuldade de leitura específica: não se sabe ao certo o que distinguiria fundamentalmente esse tema e esse capítulo daquele dedicado à "lógica dialética" (cap. 8).

Os conceitos de "antropologia da época burguesa" e "época burguesa" são o tema do capítulo 7.Aqui, Abromeit aponta que Horkheimer se contrapõe a um conceito tradicional de "antropologia" que acaba por hipostasiar uma essência humana a-histórica, assim como hipostasia também um "indivíduo abstrato". Anoção de antropologia de Horkheimer incorpora uma "teoria dialética da história" que leva em conta um período histórico específico - tal como a "época burguesa" - e admite a existência de grupos particulares que compartilham a mesma experiência social.A influência de Fromm no pensamento de Horkheimeré marcante nesse período, fazendo com que este último levasseem conta em seus escritos a relação não somente entre indivíduo, história, sociedade e grupo, como também a constituição psicológica dos indivíduos em determinada sociedade e em determinada época - destaca-se aqui a distância dos trabalhos de Peter Stirk e Helmut Dubiel sobre Horkheimer. A noção de época histórica em Horkheimer se aproximaria da noção de Marx, mas iria além, na medida em que pressuporia uma independência da "cultura" frente ao "mundo físico".

É nesse sentido que "Egoísmo e movimento de libertação" ${ }^{21}$ de Horkheimer é apontado como principal escrito do período. Segundo Abromeit, esse ensaio foi o mais influente entre os teóricos críticos do período. Tanto é assim que ele surge citado nos textos de Marcuse, Adorno e Benjamin. Horkheimer teria levado adiante seu conceito de "antropologia da época burguesa" nesse ensaio justamente porque vinculou a análise histórica dos movimentos de libertação com o surgimento do "egoísmo", apresentando ambos como tendências presentes no nascimento da sociedade burguesa. Nessas análises históricas estão presentes também, de forma marcante, os conceitos advindos da psicanálise. É principalmente com o conceito psicanalítico de "introversão" que Horkheimer compreende o discurso para as massas, em momentos revolucionários, como um "movimento de manipulação". Disso surge a noção de "nova barbárie", que possui sua historicidade no decorrer da "época burguesa" eque seencontra na tendência histórica tanto da "integração das massas", quanto da institucionalização da "crueldade racionalizada". Essas condições permitem a Horkheimer compreender que na "época burguesa primeira" se desenvolve o "fascismo no século XX".

Outro trabalho importante que também se insere nessa perspectiva da "antropologia da época burguesa" é Estudos sobre autoridade e família ${ }^{22}$. Ao examinar mais de perto essa obra, levando a sério a
[21] Horkheimer, "Egoismus und Freiheitsbewegung", op. cit.

[22] Horkheimer, M; Marcuse, H.; Fromm, E.; et al. Studien über Autorität und Familie. Forschungsberichte aus dem Institut für Sozialforschung. Mit einem Vorwort von Ludwig von Friedeburg. Reprint der Ausgabe Paris 1936. Klampen, Lüneburg 2005. 
[23] Sobre este ponto, registre-se o aparecimento, em 2013, do interessante livro de Katia Genel, Autorité et emancipation. Horkheimer et la Théorie critique (Paris: Payot \& Rivages). Como no caso de John Abromeit, a visada mais ampla da autora é a de uma reconstrução não apenas da trajetória intelectual de Horkheimer, mas do conjunto da Teoria Crítica. Katia Genel, no entanto, o faz a partir da noção de "autoridade". O que a leva a sustentar a tese de que, nessa vertente intelectual, a noção fundamental é antes a de "autoridade" do que a de "dominação", por exemplo. $O$ livro de John Abromeit se posiciona claramente contra tal possibilidade de reconstrução (ver, por exemplo, a nota 13, p. 303).

[24] Abromeit, op. cit., p.302. reivindicação de Horkheimer de que ela visa a uma articulação efetiva entre o arcabouço teórico que apresenta e a pesquisa empírica - assim como as relações destas com a noção mesma de "interdisciplinaridade" -, Abromeit novamente destaca-se de leituras tradicionais, como a de Rolf Wiggershaus. Contudo, a importância decisiva de Estudos reside no fato de a obra servir como fonte de um conjunto relevante de categorias da psicologia social para a elaboração da ideia de antropologia da época burguesa: as contribuições de Erich Fromm, especialmente suas teses psicanalíticas sobre o caráter masoquista ou autoritário como tipo dominante na Europa contemporânea, permitirão a Horkheimer uma melhor compreensão do desenvolvimento histórico de seus conceitos centrais desta primeira Teoria Crítica²3.

A conexão com a série de "reflexões sobre a lógica dialética", tema do capítulo 8, é explicitada desde o início: Horkheimer considerava o conceito de antropologia burguesa também como parte do projeto mais amplo sobre a lógica dialética ${ }^{24}$. Mas, devido aos percalços ocorridos no período - as várias mudanças do instituto, em fuga do nazismo e da guerra -, esse projeto acabou se transformando substancialmente. É nesse sentido que, para Abromeit, os escritos reunidos sobre a lógica dialética possuem um duplo caráter: por um lado, eles fazem parte dos desenvolvimentos da Teoria Crítica primeira de Horkheimer nos anos 1930; por outro, constituem também as bases para a composição da Dialética do Esclarecimento, obra publicada em 1947. As reflexões sobre lógica dialética, segundo Abromeit, partem da crítica à filosofia cartesiana e ao empirismo, retomando assim o tema da "crítica à filosofia da consciência" presente na segunda metade da década de 1920. Eé com o estudo de Hegel que Horkheimer aprofunda sua concepção de lógica dialética, movimento que termina com a "reformulação da Teoria Crítica de Marx" numa tentativa de juntar tanto a lógica categórica quanto a própria história. Essa reformulação é sintetizada no notório ensaio "Teoria Tradicional e Teoria Crítica". Para Abromeit, esse ensaio faz parte das reflexões sobre lógica dialética, o que acaba por diminuir o peso da psicanálise e da pesquisa empírica presentes em outros ensaios da década de 1930.

Finalmente, a última seção do livro trata do gradual afastamento do modelo primeiro de Teoria Crítica de Horkheimer. A tese de Abromeit é a de que uma separação de Fromm (Excurso I) e uma aproximação de Adorno (Excurso II), somadas à tese do capitalismo de Estado desenvolvida por Friedrich Pollock, passaram a influenciar decisivamente a teoria de Horkheimer, distanciando-o da Teoria Crítica primeira dos anos 1930. A tese defendida por Abromeit é que o conceito de "capitalismo de Estado" acabou ocupando um 
espaço cada vez maior nos escritos de Horkheimer, culminando esse movimento de distanciamento em O fim da razão $0^{25}$, ensaio que seria o limite entre a Teoria Crítica primeira e as primeiras reflexões que levariam à Dialética do Esclarecimento.

A centralidade que o conceito de capitalismo de Estado acabou ocupando teve consequências: Horkheimer acaba por abandonar o modelo da "dialética da sociedade burguesa" e desaparecem as distinções-chave que estruturavam seu pensamento inicial ${ }^{26}$. Mais que isso, Horkheimer abandona as análises dos "potenciais revolucionários" que pautaram o início da era burguesa de tal modo que o conceito de capitalismo de Estado e "sua lógica imanente" permite a ele igualar as diferenças entre "pensadores opostos do mesmo período", assim como as diferenças de "pensadores e conceitos de diferentes períodos". Perde-se assim a característica fundamental de sua primeira Teoria Crítica: a dialética da sociedade burguesa e sua historicidade. Abromeit destaca também que essa mudança está diretamente relacionada à grande influência das "Teses sobre História" 27 de Walter Benjamin tanto em Horkheimer quanto em Adorno. A influência desse texto levou os autores a interpretarem o passado a partir do presente, acabando por levá-los a um processo de "des-historicização" de seu pensamento.

Por isso, com o modelo da Dialética do Esclarecimento, segundo Abromeit, perde-se o que há de mais rico para contribuir com a teoria social contemporânea.É nesse sentido que a Teoria Crítica primeira de Horkheimer da década de 1930 pode "contribuir para uma renovação da Teoria Crítica". Com isso, o posicionamento de Abromeit a respeito da interpretação da obra de Horkheimer surge de modo marcante: a crítica à Dialética do Esclarecimento é acertada quando se refere somente a essa obra. Essa crítica, como mostra Abromeit, não se estende aos escritos anteriores a Ofim da razão. Daí que ele afirme que o mais interessante da obra da primeira geração da Teoria Crítica está no projeto da década de 1930.

O gênero "biografia intelectual" permite a John Abromeit resolver, pela primeira vez e de maneira convincente, intrincados problemas teóricos dos estudos sobre Horkheimer, como é o caso do famoso “juízo existencial" que ocupa posição de destaque no ensaio "Teoria Tradicional e Teoria Crítica"28. Mostra-se igualmente capaz de dar explicação convincente e coerente em aspectos para os quais as fontes são escassas, como é o caso do capítulo 5 do livro, que trata da integração da psicanálise na teoria social de Horkheimer (mesmo se aqui fica a impressão de que a importância de Reich foi subestimada, por exemplo). Não por acaso, portanto, John Abromeit encerra o livro apontando para um modelo de renovação da Teoria Crítica que é aguardado com expectativa: "Um novo modelo de Teoria Crítica necessitaria
[25] Horkheimer, M. "The end of reason". Studies in Philosophy and Social Sciences, vol. IX, Nova York, 1942

[26] Abromeit, op.cit., p.395.

[27] Benjamin, W. Obras Escolhidas; vol.r. Magia e técnica, arte e política. Ensaios sobre literatura e história da cultura. São Paulo: Brasiliense, 1994.

[28] Abromeit,op.cit., p.330. 
preservar as tradições do materialismo histórico e da psicanálise junto com os melhores aspectos da tradição política democrática liberal" 29 . Mas, antes de exigir do autor que continue a trilha que ele próprio abriu, cabe antes recomendar à leitora e ao leitor que aproveite a leitura deste livro excepcional.

MARCOS NOBRE é professor no Departamento de Filosofia do IFCH da Unicamp e pesquisador do Cebrap.

ADRIANO JANUÁRIO é doutorando no programa de pós-graduação em Filosofia da Unicamp. RAPHAEL CONCLI é mestrando no programa de pós-graduação em Filosofia da Unicamp. PAULO YAMAWAKE é mestrando no programa de pós-graduação em Filosofia da Unicamp. 